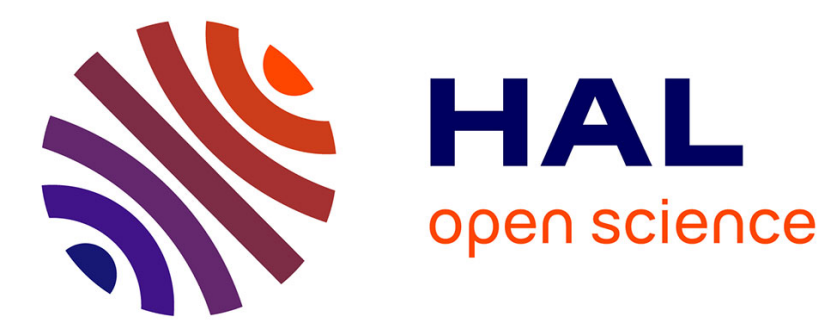

\title{
Numerical modelling of a realistic annular effusion cooling system
}

Gaétan Crouzy, Fabien Desarnaud, Emmanuel Laroche, Pierre Millan

\section{To cite this version:}

Gaétan Crouzy, Fabien Desarnaud, Emmanuel Laroche, Pierre Millan. Numerical modelling of a realistic annular effusion cooling system. Propulsion and Energy 2019, Aug 2019, INDIANAPOLIS, United States. 10.2514/6.2019-4259 . hal-02396972

\section{HAL Id: hal-02396972 https://hal.science/hal-02396972}

Submitted on 6 Dec 2019

HAL is a multi-disciplinary open access archive for the deposit and dissemination of scientific research documents, whether they are published or not. The documents may come from teaching and research institutions in France or abroad, or from public or private research centers.
L'archive ouverte pluridisciplinaire HAL, est destinée au dépôt et à la diffusion de documents scientifiques de niveau recherche, publiés ou non, émanant des établissements d'enseignement et de recherche français ou étrangers, des laboratoires publics ou privés. 


\title{
Numerical modelling of a realistic annular effusion cooling system
}

\author{
G. Crouzy ${ }^{1}$ and F. Desarnaud ${ }^{2}$ \\ SAFRAN Tech, 1 rue Geneviève Aubé, 78114, Magny-les-Hameaux, France \\ E. Laroche ${ }^{3}$ and P. Millan ${ }^{4}$ \\ ONERA/DMPE, Université de Toulouse, F31055 Toulouse, France
}

\begin{abstract}
An experimental test campaign has been conducted by Safran and ONERA in order to generate a database on an annular effusion cooling system. Different effusion cooling patterns have been tested in various flow field conditions, representative of those encountered in real aeronautical combustors in terms of Reynolds number in the perforations, blowing ratio and momentum ratio. This paper presents the numerical modelling of three tests conducted in the same flow field condition for three effusion cooling patterns, featuring different compound angles: $0^{\circ}, 4^{\circ}$ and $90^{\circ}$. Comparisons are made between the experimental wall temperature measured by infrared thermography and the associated RANS simulations. The cooling efficiency is overestimated by RANS simulations, especially for high compound angle values. Comparisons of the cooling film development mechanisms between these three simulations are presented by analyzing the temperature field close to the multiperforated wall.
\end{abstract}

\section{Nomenclature}

$\beta \quad=$ compound angle

$\varphi \quad=$ wall heat flux $\left(\mathrm{W} / \mathrm{m}^{2}\right)$

$\varphi 0=$ wall heat flux upstream the multiperforated area $\left(\mathrm{W} / \mathrm{m}^{2}\right)$

$\theta=$ dimensionless temperature

$T_{\text {cold }} \quad=$ fluid temperature in the cold channel $(\mathrm{K})$

$T_{\text {hot }} \quad=$ fluid temperature in the hot channel $(\mathrm{K})$

\section{Introduction}

The combustor is a key component of an aircraft jet engine or a helicopter turbine. It undergoes very high thermal stresses and its walls, the liner, need to be cooled down in order to extend its lifetime. The technique currently used is effusion cooling which consists in injecting cold air through thousands of submillimetric holes drilled into the liner. The small jets resulting from this injection merge and create a cooling film, running along the liner's inner surface and protecting it from the high temperature gases. Although it is an efficient technic, engine manufacturers might be willing to reduce the amount of air dedicated to cooling, for different purposes. It can enable to inject more air directly into the primary zone, leading to leaner combustions and lower polluting emissions. Or it can allow to increase the amount of dilution air, in order to optimize the turbine inlet temperature profile. For both reasons, it is necessary for manufacturers to improve the efficiency of the cooling film which can be reached by searching for better hole patterns. Indeed, the film formation is highly dependent on the way holes are drilled into the liner. In particular, it has been shown that compound angle has a major impact on the film's efficiency [1-3]. This angle, if not equal to zero, leads

\footnotetext{
${ }^{1} \mathrm{PhD}$ Student, gaetan.crouzy@safrangroup.com

${ }^{2}$ Thermomechanical Engineer, fabien.desarnaud@ safrangroup.com

${ }^{3}$ Research Engineer, emmanuel.laroche@onera.fr

${ }^{4}$ Director of Multi-Physics for Energetics Department, pierre.millan@onera.fr
} 
to a non-zero azimuthal velocity component for the cold air injection. Therefore, the air is flowing along the liner's inner surface with a rotational movement. In this case, the film is stronger and isolates the liner from the hot environment better [4, 5].

During an engine development, manufacturers need to run simulations on full combustor, involving effusion cooling. However, representing thousands of holes on a liner, leads to CPU demanding meshes, because of their high number and their small size compared to the combustor's diameter. Consequently, engine manufacturers usually do not represent holes on the liner and instead use effusion cooling models [6-9] or correlations [10, 11] able to represent heat fluxes at a cheaper cost. However, the building of such models or correlations is limited by the current lack of experimental data, especially when it involves new hole patterns. In this framework, Safran supported an experimental test campaign, performed by Onera, aiming to provide a detailed database for effusion cooling on a cylindrical configuration. Previous correlations or models were developed for axial injection on plane walls. Here, the database features several different compound angles on multiperforated walls with cylindrical shapes. Moreover, the flow field conditions that have been selected are representative of an aeronautical combustor in terms of Reynolds number in the holes, blowing ratios and momentum ratios.

The first goal of this article is to briefly present this test campaign and to show selected results. However, in order to build future accurate models or correlations for effusion cooling, it is necessary to evaluate the heat flux at the wall, which has not been measured experimentally. Thus, the second goal of this article is to present the associated RANS simulations, which will give access to this quantity among others. Comparisons between the cylinders' wall temperature from simulations and from the experimental measurements will be made. Moreover the calculated fluid temperature field close to the wall will be analyzed in order the compare the cooling film formation between different compound angles.

\section{The experimental test campaign}

A design of experiment has been created in order to assess the effect of various geometrical and aerothermal parameters on effusion cooling. In total, 177 tests have been performed, involving 51 flow field conditions on 12 different test cylinders, each with its own hole pattern (Fig. 1), which is characterized by the following parameters (Fig. 2):

- penetration angle : $\alpha$

- compound angle : $\beta$

- porosity : $\sigma$ (ratio between the total holes' entry area and the total wall's area)

- hole diameter : $d$

- lateral spacing : $s$

- longitudinal spacing : $p$

- number of rows

- number of perforations per row

- thickness of the wall $: e$

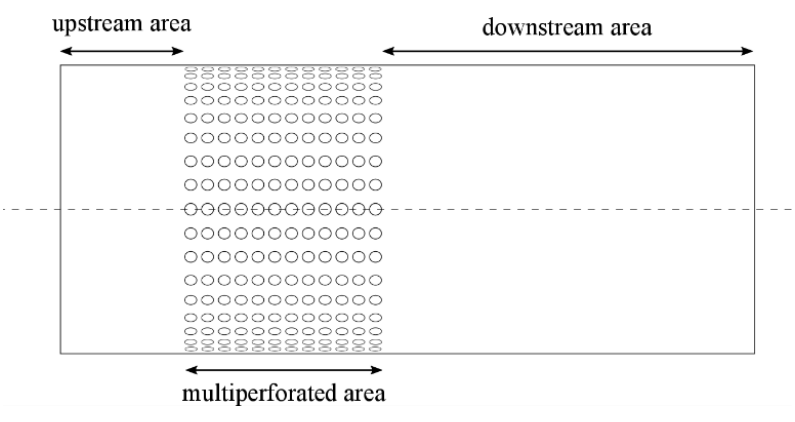

Fig. 1 Test cylinder featuring a multiperforated area. 


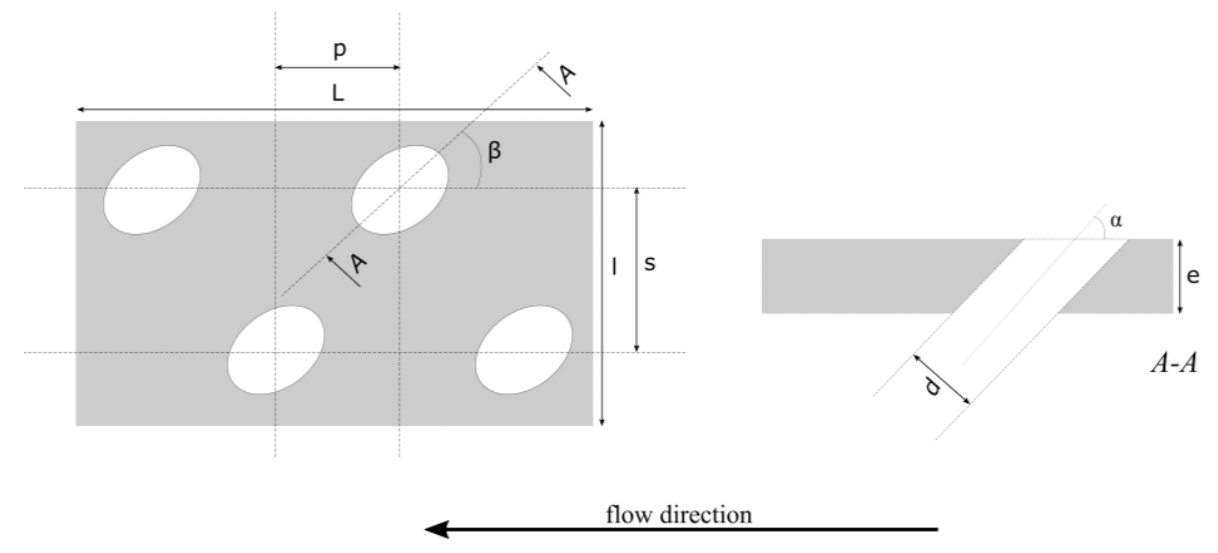

Fig. 2 Geometrical parameters of a hole pattern.

The test rig is shown in Fig. 3. The perforated test cylinder separates the hot and cold air channels. Due to the pressure difference, cold air is sucked into the hot channel through the cylinder's holes. Thus, the wall is cooled down by a cooling film on its inner surface. An optical access allows to measure the cylinder external wall temperature by infrared thermography (Fig. 4 (right)). The uncertainty of measurement has been evaluated around 6K. An azimuthal average of the infrared temperature mapping gives access to the temperature evolution along the cylinder, which can be plotted as in Fig. 4 (left) with a dimensionless temperature $\theta$ defined as:

$$
\theta=\frac{T-T_{\text {cold }}}{T_{\text {hot }}-T_{\text {cold }}}
$$

If the test cylinder is cooled down efficiently, its temperature is close to the cold fluid temperature and $\theta$ is close to 0 . On the contrary, without cooling the latter is 1 .

Moreover, a heating rod is located in the center of the hot channel. Its goal is to generate a radiative heat flux, to reproduce the effect of the flame, even if this heat flux is lower than in a real combustor. It has only been turned on for a few tests.

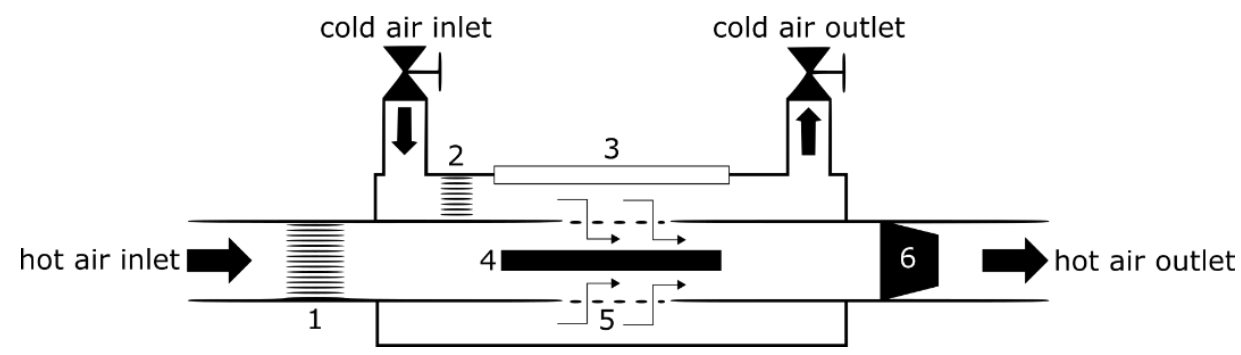

Fig. 3 Experimental rig description (1,2-honeycombs; 3-window; 4-heating rod; 5-test cylinder; 6-outlet nozzle) 

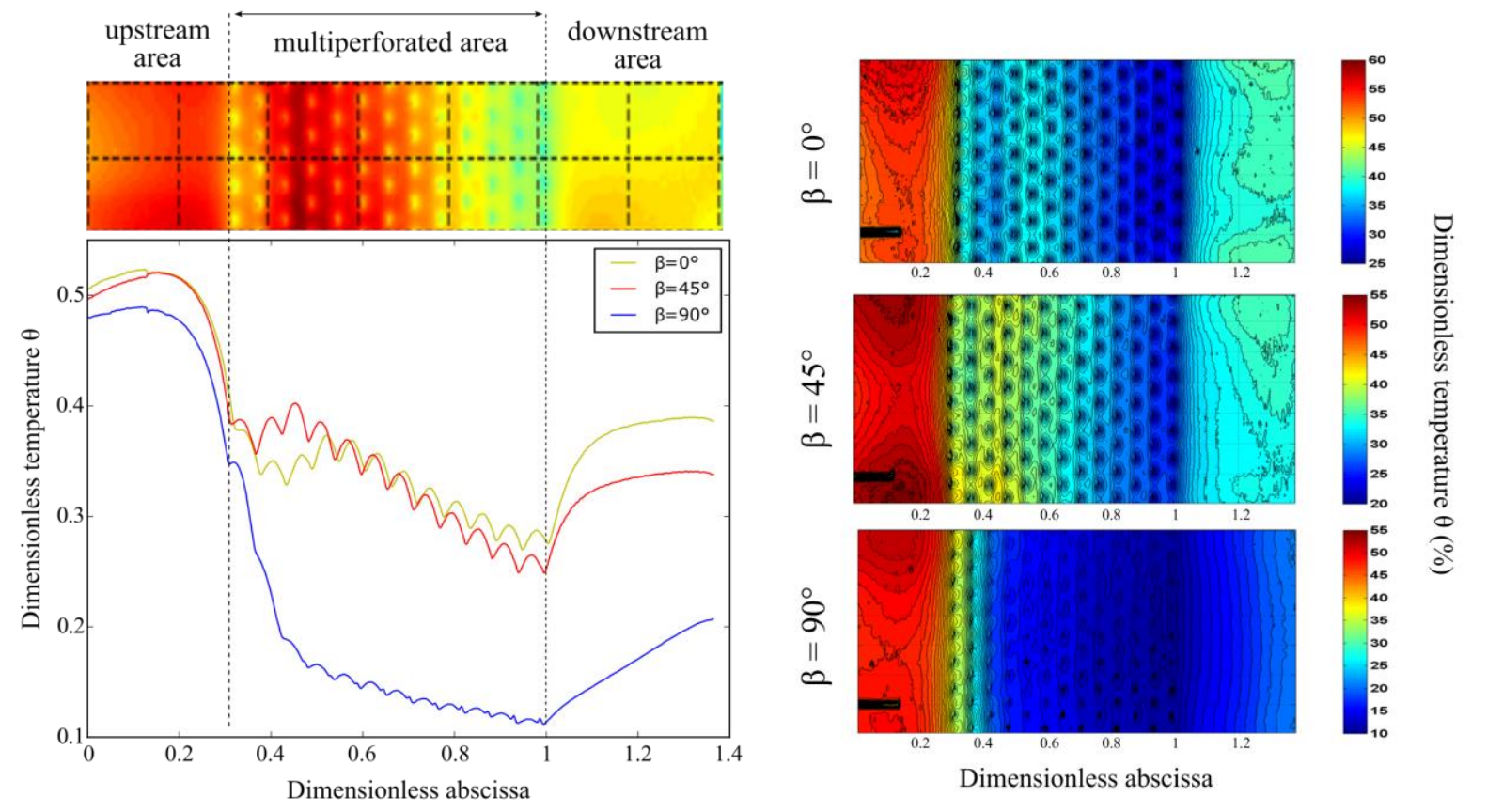

Fig. 4 Left: Effect of the compound angle over the laterally averaged dimensionless temperature. Right: comparison between the wall temperature fields measured by infrared thermography, for three compound angles.

Regarding the flow field conditions, the parameter range is summarized in Table 1. Effusion cooling is specifically defined by three dimensionless parameters: the blowing ratio, which goes from 5 to 13 , the momentum ratio, from 5 to 65 and the Reynolds number in the holes, from 6000 to 12000. The values of these dimensionless parameters are the same order of magnitude as in real aeronautical combustors, even if temperature, pressure, and mass flow rate are lower. Moreover, in the cold channel the Reynolds number ranged from 22000 to 68000 and in the hot channel from 32000 to 85000 .

First conclusions on the experimental database dealing with the compound angle are presented in Fig. 4: three different test cylinders have been placed in the same aerothermal condition. Their only difference relies in the compound angle value, varying from $0^{\circ}$ to $90^{\circ}$. For a value of $45^{\circ}$, the compound angle improves the efficiency of the cooling film downstream the multiperforated area. When this angle reaches $90^{\circ}$, the improvement is also very significant in the multiperforated area, demonstrating the high cooling efficiency of such a geometry. Another difference can be seen at the transition between the multiperforated and the downstream areas: for an angle of $0^{\circ}$ and $45^{\circ}$, temperature evolution shows a steep increase, representative of the sudden mix between the hot air and the cooling film which is not sustained anymore by the cold air injection. On the contrary, for an angle of $90^{\circ}$, this jump in temperature does not appear, showing a more gradual mixing thanks to a stronger cooling film structure.

\begin{tabular}{|l|c|}
\hline \multicolumn{1}{|c|}{ Parameter } & Range \\
\hline Cold air mass flow & $100-900 \mathrm{~g} / \mathrm{s}$ \\
\hline Hot air mass flow & $200-570 \mathrm{~g} / \mathrm{s}$ \\
\hline Cold air temperature $\mathrm{T}_{\text {cold }}$ & $300-400 \mathrm{~K}$ \\
\hline Hot air temperature $\mathrm{T}_{\text {hot }}$ & $750-900 \mathrm{~K}$ \\
\hline Pressure in the cold channel & $7-19 \mathrm{bar}$ \\
\hline Pressure difference between the hot and cold channels & $140-1440 \mathrm{mbar}$ \\
\hline Relative pressure difference between the hot and cold channels & $1-20 \%$ \\
\hline Blowing ratio & $5-13$ \\
\hline Momentum ratio & $5-65$ \\
\hline Reynolds number in the holes & $6000-12000$ \\
\hline
\end{tabular}

Table 1 Flow field parameter variations. 


\section{Inlet conditions measurement and evaluation}

In order to be able to reproduce these tests by numerical simulations, it is necessary for the boundary conditions to be perfectly known. During the campaign, the velocity profiles in both channels have been measured by LDA at the entry of the test cylinder, more precisely at a location corresponding to the first row of holes. The dimensionless velocity profile in the cold channel is shown in Fig. 5 (left) which has been measured for only one flow field condition. To perform a RANS simulation of any test point, it is then necessary to extrapolate this profile to the proper flow field conditions. Thus, for each simulation, the dimensionless profile is multiplied by the mean flow velocity and imposed at the cold channel inlet of the computational domain.

In the hot channel, measurements for two different mass flow rates show fully-axial and homogeneous velocity profiles (Fig. 5 (right)). Being homogeneous, the hot velocity profile does not require an extrapolation and a uniform inlet mass flow is prescribed.

However, the temperature profile has not been measured, and a separate study has proven that it is necessary to take it into account in the hot channel. In spite of the thermal insulation, significant heat losses occur in the rig, upstream of the test cylinder, creating a thick thermal boundary layer which runs along the cylinder inner wall and has an impact on heat transfers. Some coupled simulations of the rig enabled to determine the right temperature profile for each flow field condition, at a location corresponding to the first row of holes on the cylinder. Figure 6 shows this profile for a particular test point with a mass flow rate in the hot channel of $500 \mathrm{~g} / \mathrm{s}$. The appropriate profile will be prescribed as a thermal condition at the entry of the hot channel for each RANS simulations.
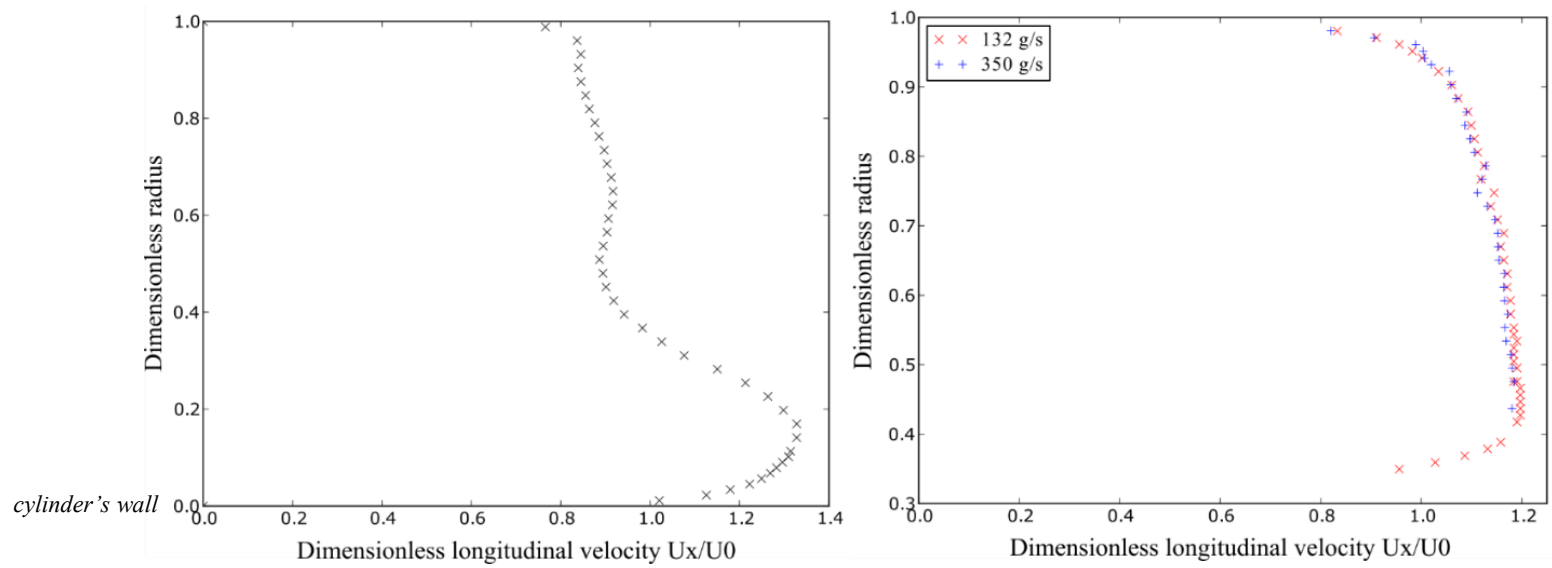

Fig. 5 Left: experimental dimensionless longitudinal velocity profile in the cold channel (mean flow velocity: $\mathrm{U0}=9.43 \mathrm{~m} / \mathrm{s}$ ). Right: experimental dimensionless longitudinal velocity profile for two mass flows in the hot channel.

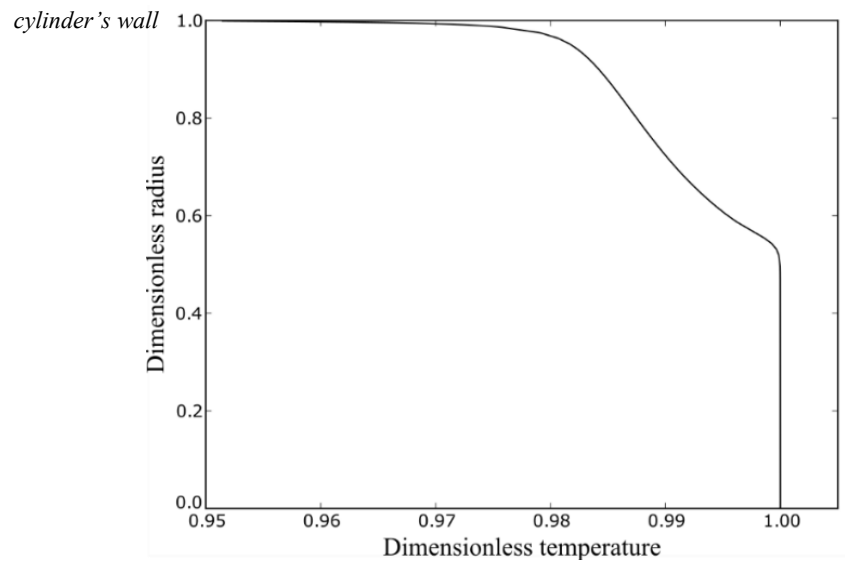

Fig. 6 Dimensionless temperature in the hot channel at an abscissa corresponding to the first row of holes (mass flow rate $=\mathbf{5 0 0} \mathrm{g} / \mathrm{s})$. 


\section{RANS simulations}

\section{A. Computational domain and mesh}

The numerical restitution of the test campaign is done by conjugate RANS simulations using ANSYS Fluent. The computational domain is shown in Fig. 7. Because of the rotational periodicity of the configuration, the domain is represented by a $5^{\circ}$ angular sector of the test cylinder, featuring thirteen holes, in two longitudinal rows. A fluid channel with periodic lateral faces is present on both cylinder sides. The mesh shown in Fig. 8, including the fluid and solid domain, contains 13.5 million elements. Close to the wall, inflation layers with prisms are created. The first cell height is $2 * 10^{-6}$ meters, leading to a y+ value less than one over the cylinder walls and between one and two in the holes. A Menter k- $\omega$ SST turbulence model is used, as in Ref. [8, 10]. At the cold channel inlet, the appropriate velocity profile is prescribed with a homogeneous temperature profile. At the hot channel inlet, the appropriate temperature profile is prescribed with a homogeneous velocity profile. For both inlets a turbulence intensity of 5\% is prescribed as well as a turbulent viscosity ratio of 10 . The inlet surfaces are located 100 diameters upstream the first hole. For both channels, outlet is defined as a static pressure outlet boundary condition.

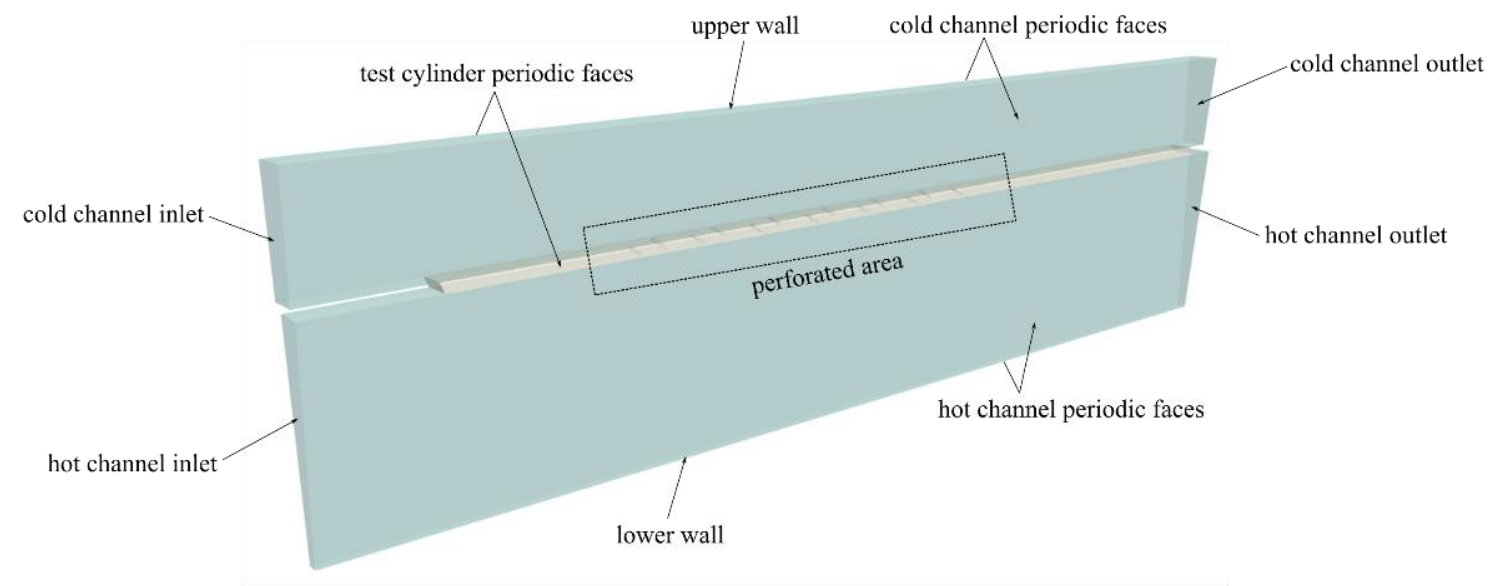

Fig. 7 Computational domain and boundary conditions.
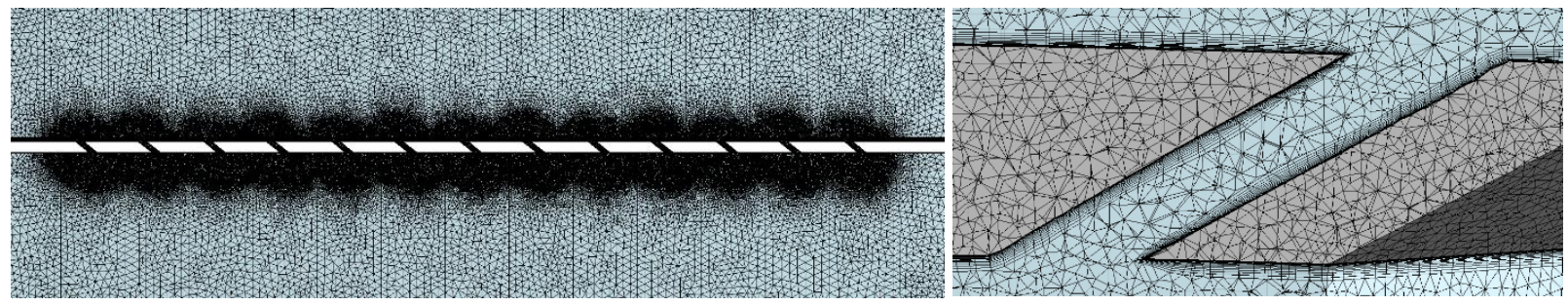

Fig. 8 Left: mesh in the fluid domain around the multiperforated area. Right: details of the mesh in the fluid and solid domain in and around a single perforation.

\section{B. Comparisons between measured and calculated wall temperature}

The effects of the compound angle over the wall temperature for one given flow field condition are presented hereafter. Three different cylinders, with different compound angle have been tested. Their wall temperatures measured by infrared thermography and calculated by the RANS simulations, are compared in Fig. 9.

For each test cylinder, simulations show acceptable wall temperature upstream of the multiperforated area, compared to the measurements. From the first row of holes, the effect of the compound angle can be seen on the calculated temperature. For a fully axial injection cylinder $\left(\beta=0^{\circ}\right)$, temperature matches the measurements, showing that the cooling film is well estimated. But, with a non-zero compound angle, the cooling film efficiency is overestimated by the simulation. Thus, for $\beta=45^{\circ}$, after the seventh row of holes, calculated temperature drops compared to the experiment. For $\beta=90^{\circ}$, the cylinder's temperature is underestimated from the first row of holes. In 
spite of these underestimations, in each case the temperature evolution is rather well estimated by the code. However, downstream the multiperforated area, where a pure mixing between the film and the hot air occurs, the cooling efficiency is overestimated for 0 and $45^{\circ}$, probably because the film does not mix enough with the hot air in the simulation. On the contrary for $90^{\circ}$, simulations predict a significant temperature climb, while the measurements show that the cooling remains efficient all along the downstream area.

These results show that RANS calculations can predict the temperature evolution in a multiperforated area, but when a compound angle is involved, especially for high values, the cooling efficiency can be underestimated. On the contrary, in the downstream area, for low values of $\beta$, the mix between the film and the hot air seems underestimated and for high values, it seems overestimated.
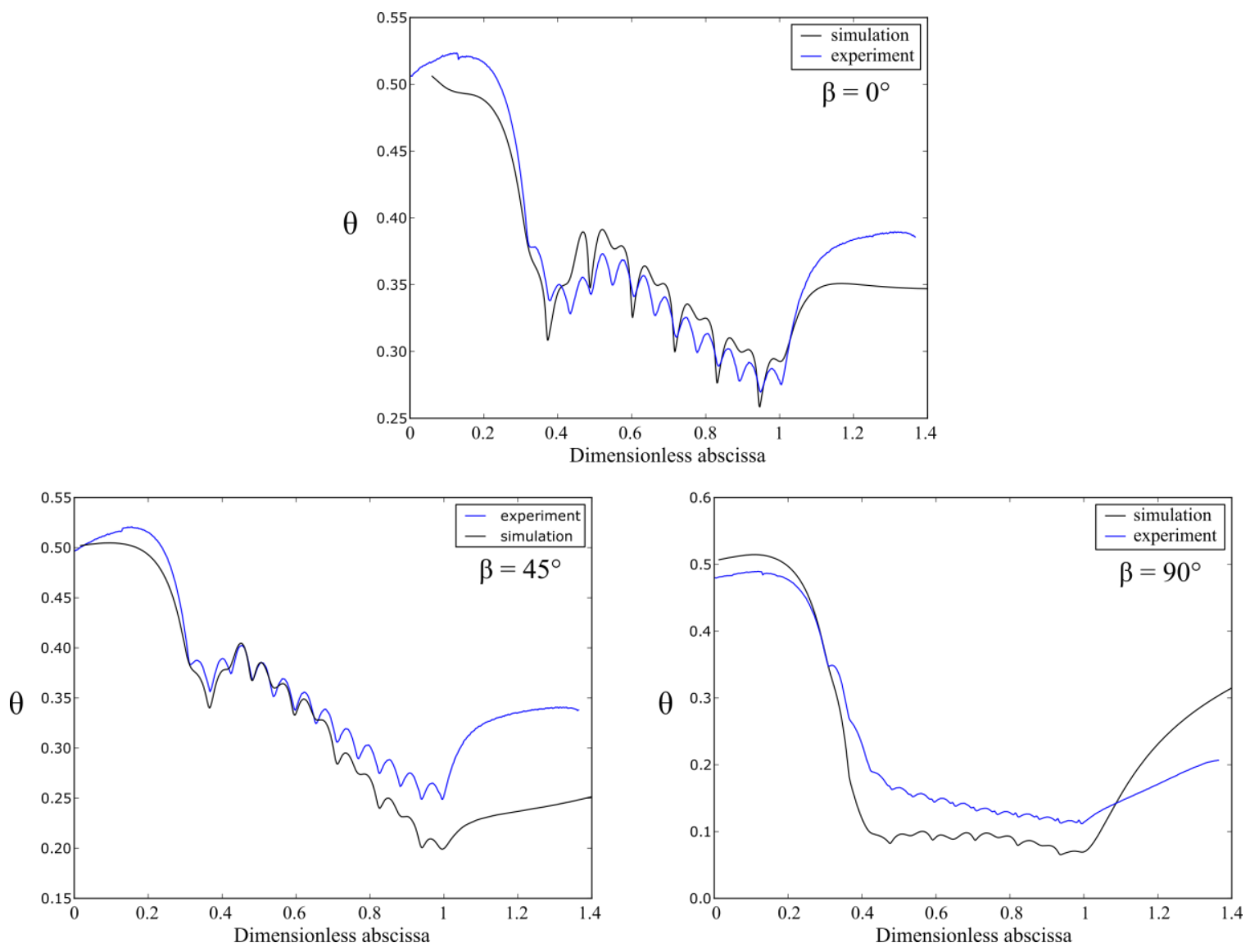

Fig. 9 Dimensionless temperature along the test cylinder's wall for different compound angles. Comparison between experimental measurements and RANS simulations.

\section{RANS simulations detailed analysis}

\section{Wall temperature and heat flux}

The temperature field over the cold side of the test cylinder for each of the three simulations is presented in Fig. 10. The temperature field over the hot side of the test cylinder is not displayed because it is very similar to the one over the cold side. Indeed, the test cylinder thickness is small, leading to a Biot number of 0.06. 
flow direction

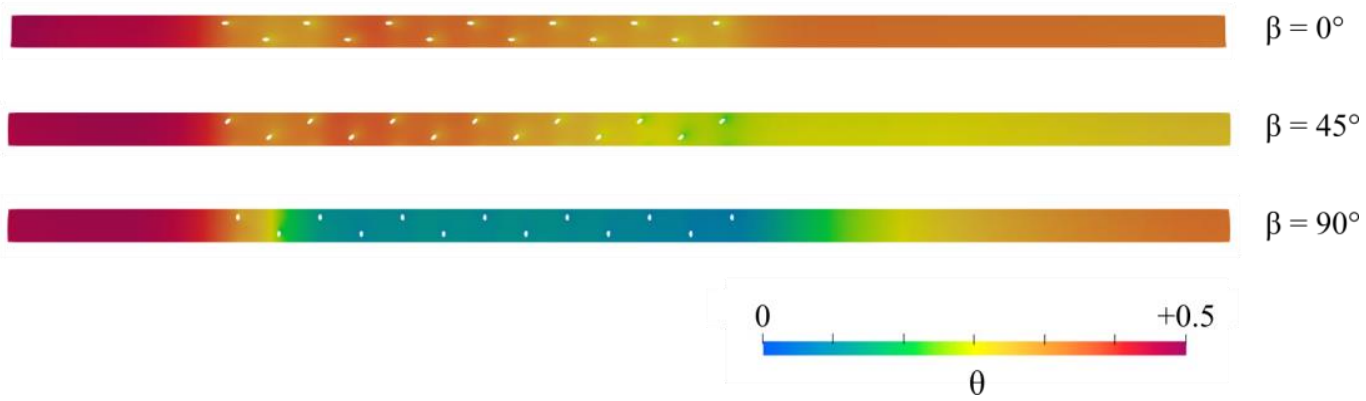

Fig. 10 Temperature field over the cold side of three compound angles from RANS simulations.

Figure 11 shows the heat flux over the cold side of the test cylinder. It is made dimensionless by dividing by the absolute value of the heat flux upstream the multiperforated area $|\varphi 0|$. Thus, it is possible to see the effect of effusion cooling over the heat exchanges. On this side of the cylinder, the flux is negative, meaning that the cylinder is cooled down. High values of the heat flux can be seen downstream each hole which was expected, regarding Ref. [12] study.

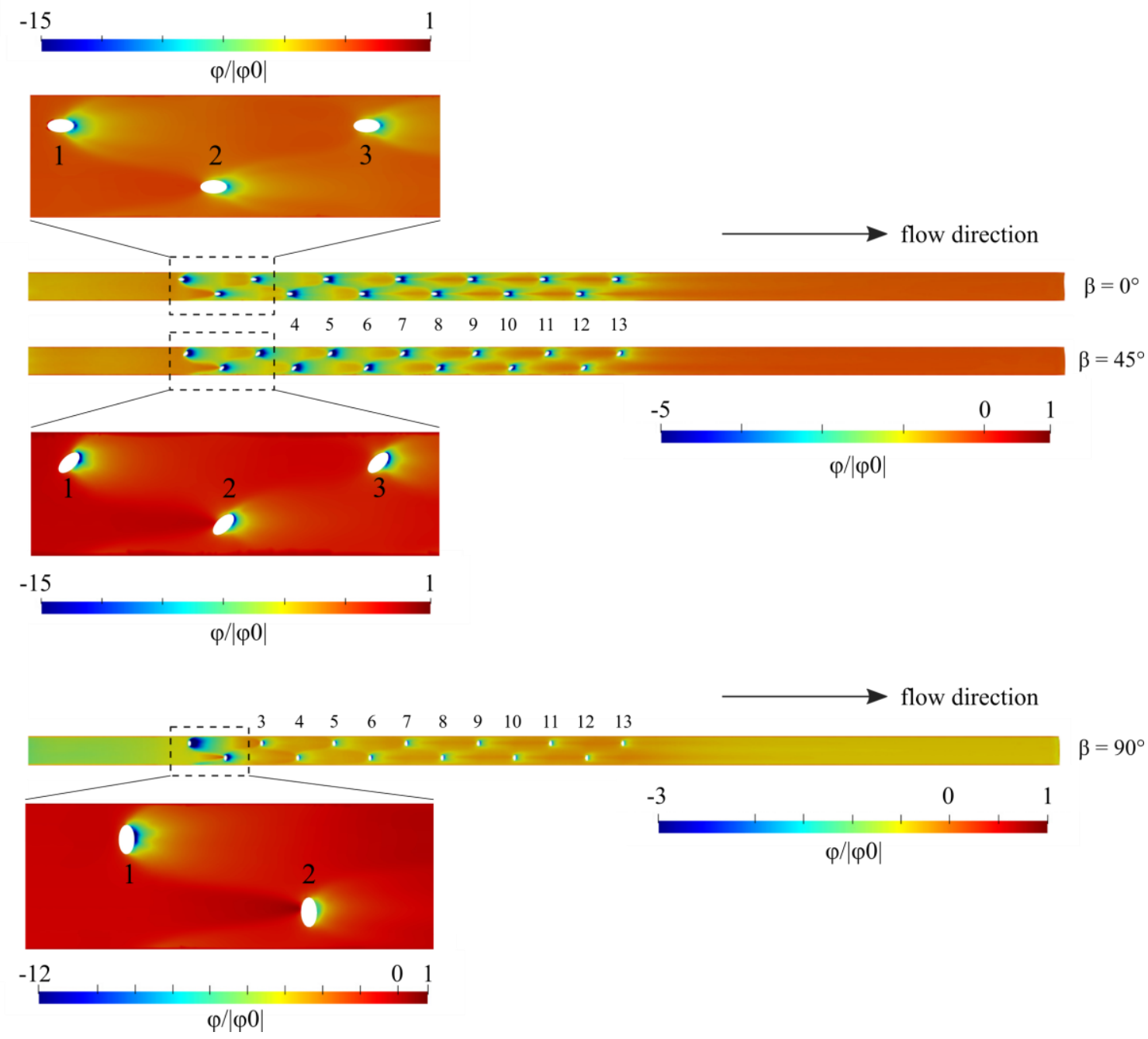

Fig. 11 Heat flux over the cold side of a cylinder from a conjugate RANS simulations. Effect of the compound angle. 
The dimensionless heat flux on the hot side of the test cylinder is shown in Fig.12. Heat exchanges for a $90^{\circ}$ compound angle are lower in the multiperforated area because the film is highly efficient and the fluid temperature close to the wall is close to the wall temperature. On the contrary, for $0^{\circ}$ and $45^{\circ}$ compound angles, the difference between the fluid temperature close to the wall and the wall, leads to higher heat exchanges. This difference decreases slowly along the multiperforated area, as the cooling film is created. On this side, heat flux heterogeneities can be seen. The assumption that the injected cold air does not spread well between the rows can be made. This will be confirmed by observations of the temperature field in the hot channel, presented later in this paper.

In Fig. 12, for a $0^{\circ}$ and $45^{\circ}$ compound angle, a high flux spot can be seen downstream the third hole, which can also been seen Fig. 13. For a $90^{\circ}$ compound angle, there is a very high heat transfer at the upstream border of the second hole. Again, observations of the temperature field in the hot channel will bring explanations.

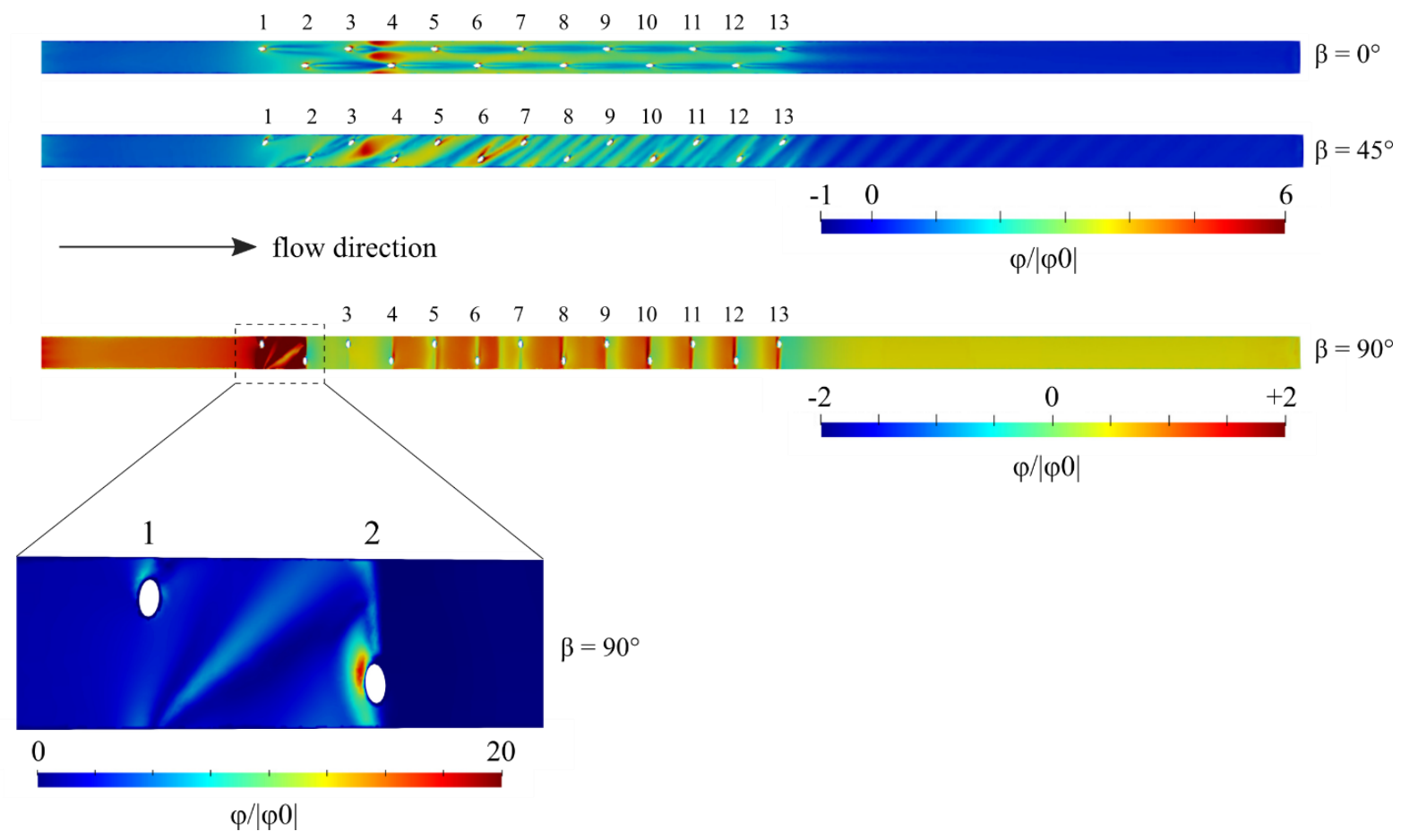

Fig. 12 Heat flux over the hot side of a cylinder from a conjugate RANS simulations. Effect of the compound angle. 


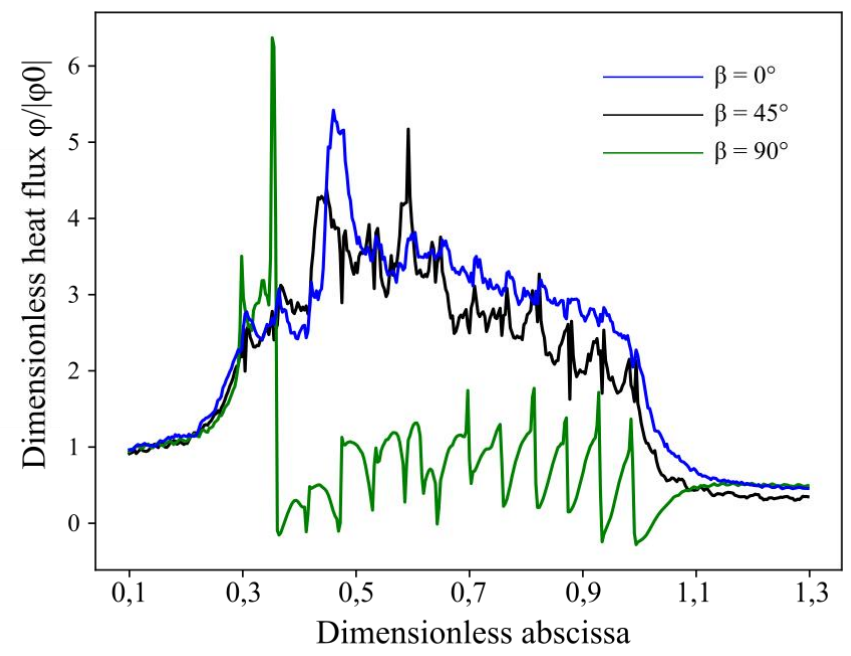

Fig. 13 Dimensionless heat flux along the hot side of the cylinders, for three compound angles.

\section{Temperature field in the hot channel}

Figure 14 displays the temperature field in the hot channel, over a slice located between the two longitudinal rows of holes. It should be recalled that at the hot channel inlet, a temperature profile has been prescribed, resulting in a non-homogeneous flow field upstream the multiperforated area $[\mathbf{A}]$ (see section about the inlet conditions). For a $90^{\circ}$ compound angle, downstream hole number 2 , a thick cold air layer is quickly created, protecting very efficiently the wall [B]. On the contrary, for a $45^{\circ}$ compound angle, the cold air mixes much more with the incident hot air. Thus an effective cold air layer close to the wall takes more distance to be created. Even after the thirteenth hole, this layer [C] is less thick and is hotter than the one created with a $90^{\circ}$ compound angle. When the injection is fully axial, even downstream the multiperforated area, the film temperature close to the wall remains warm [D]. It shows that the cold air being injected, does not spread laterally between the two longitudinal rows of holes, leading to an unprotected surface of the cylinder.

Marker [E] shows hot air being sucked under the cold air jets, and being brought directly in contact with the wall which can be seen better in Fig. 15. These hot air pockets are responsible for the high heat flux spots, seen on the hot side of the cylinder Fig. 12 and Fig. 13.

Figure 14 also shows the behavior of the cooling film, downstream the multiperforated area. For a $90^{\circ}$ compound angle, the film is quickly destroyed and hot air is brought to the wall. On the contrary, for $0^{\circ}$ and $45^{\circ}$, the cold air is maintained close to the wall further after the multiperforated area.

These results show that a better protection is provided by a high compound angle injection in the multiperforated area. Downstream, the simulations do not reproduce well the cooling film behavior. For a $0^{\circ}$ and $45^{\circ}$ compound angle, the rise in temperature is underestimated by the simulations. Consequently, it seems that the cooling film does not mix enough with the hot air, compared to the experiment. On the contrary, for a $90^{\circ}$ compound angle, the wall temperature rises too quickly, showing that the mixture between the cooling film and the hot air might be overestimated by the simulation. 

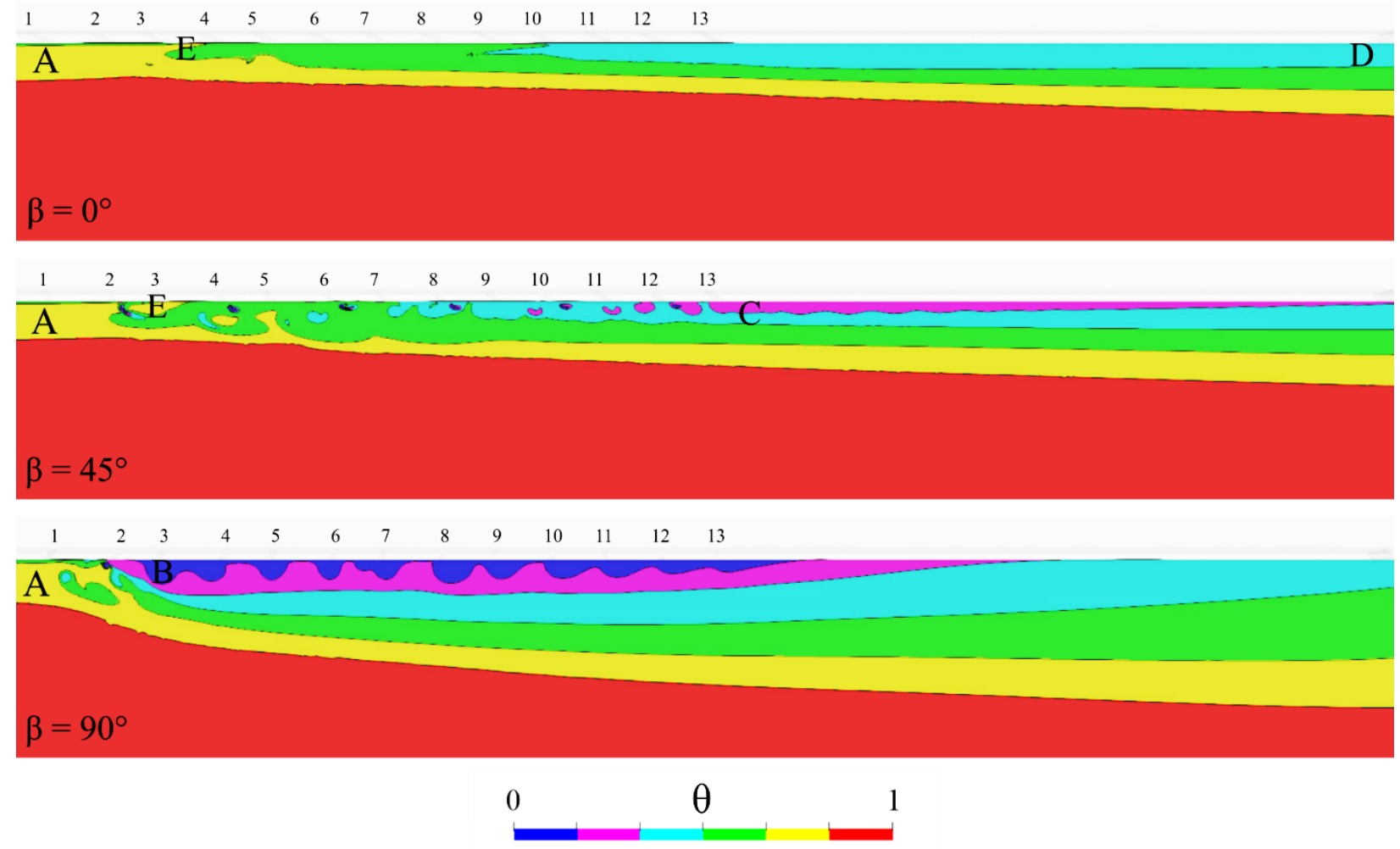

Fig. 14 Temperature field in the hot channel over a slice between the two longitudinal rows.

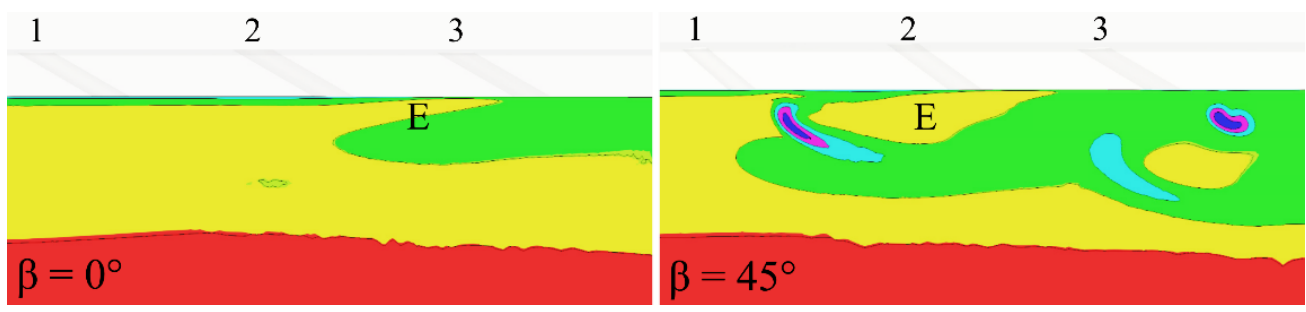

Fig. 15 Details of the temperature field close to the wall for $0^{\circ}$ and $45^{\circ}$ compound angle, at the beginning of the multiperforated area.

Figure 16 shows six slices perpendicular to the jet coming out of hole number 2 for a $90^{\circ}$ compound angle. Consequently, the slices are parallel to the main flow direction in the hot channel. Slice number 1 is located at the hole exit, while slice number 6 is located closer to the lateral wall of the computational domain. These slices show how the cold air jet $[\mathbf{E}]$ creates, close to the wall, an efficient barrier against the incident hot air $[\mathbf{A}]$. The latter is deviated deeper in the channel and brought far from the wall. Thus, cold air stays close to the wall and creates a protective layer downstream of hole number two, $[\mathbf{B}]$. The efficiency of this injection is great because the hot and the cold air do not mix a lot.

In slice 2, marker [C], a small amount of hot air is being brought in contact with the wall. It increases severely the heat exchange locally, at the upstream border of the second hole, which can be seen in Fig. 12 and Fig. 13. Marker [D] refers to the plume of the jet coming out from hole number 1, gradually mixing with the hot air. 


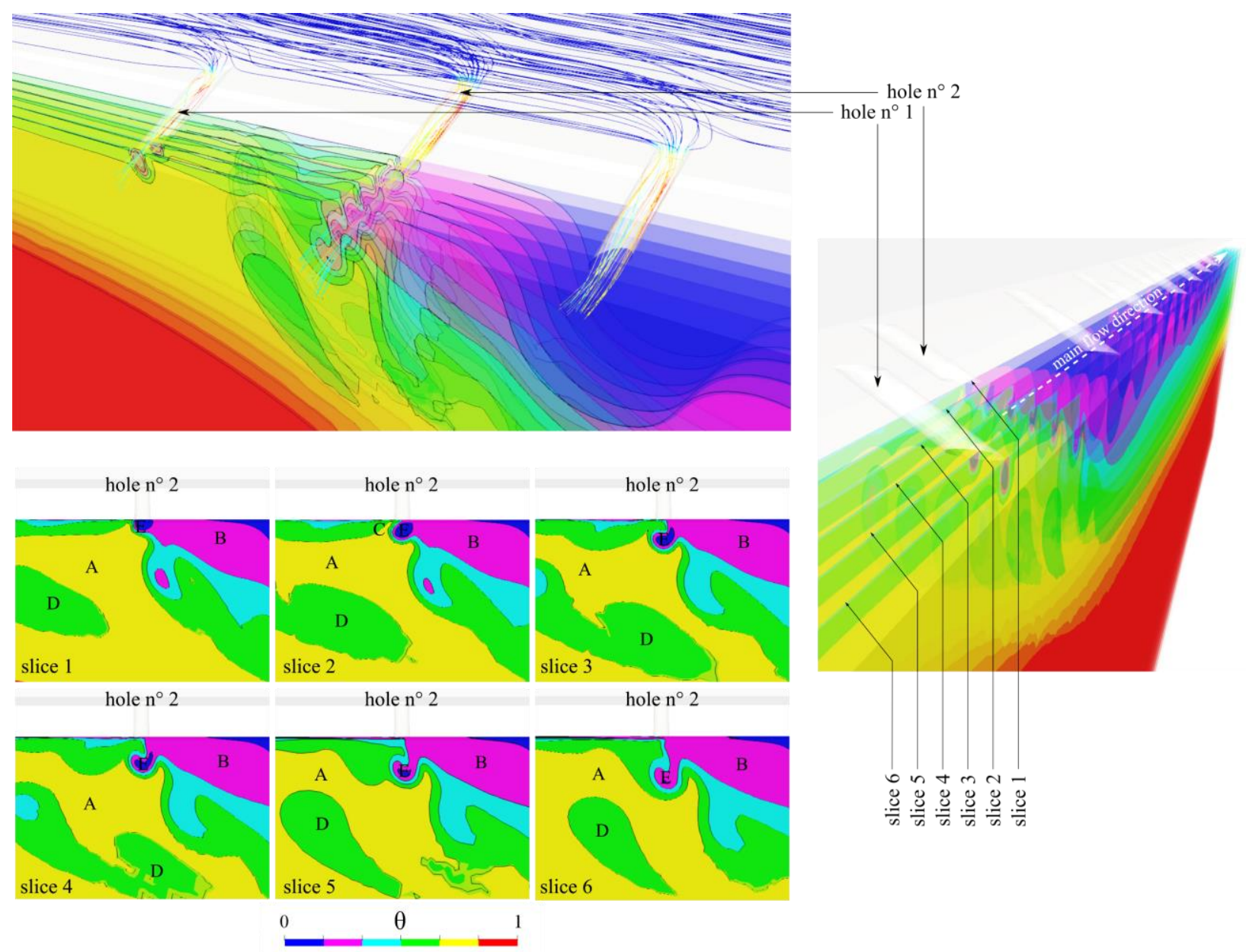

Fig. 16 Conjugate RANS simulation for a $90^{\circ}$ compound angle: temperature field in the hot channel over six slices perpendicular to the jets. Streamlines are colored by the velocity magnitude.

Figure 17 shows the temperature field in the hot channel for a $45^{\circ}$ compound angle. The slices are perpendicular to the jets. Slice number 1 is located at the exit of hole number 2, while slice number 6 is located a bit upstream hole number 3. Marker [A] refers to the cold air jet coming out from hole number 2. The jet penetrates into the hot channel, thus cold air is not kept close to the wall. It finally mixes with the cold air coming from hole number $1[\mathbf{B}]$ which is already partially mixed with the incident hot air. They can mix because of the $45^{\circ}$ compound angle which makes the jets aligned. The same process occurs for the jet from hole number $3[\mathbf{D}]$, which mixes with $[\mathbf{C}]$ a bit downstream the last displayed slice. Consequently, the summation of all these aligned jets creates a protecting cold air layer after a few holes, but the lateral spreading is not significant. This confirms the assumption made in the previous section. It should be noted that because of the lateral periodicity of the calculation domain, the same jet can appear at different locations on the same slice. This is why marker $[\mathbf{B}]$ and $[\mathbf{C}]$ appear twice. 


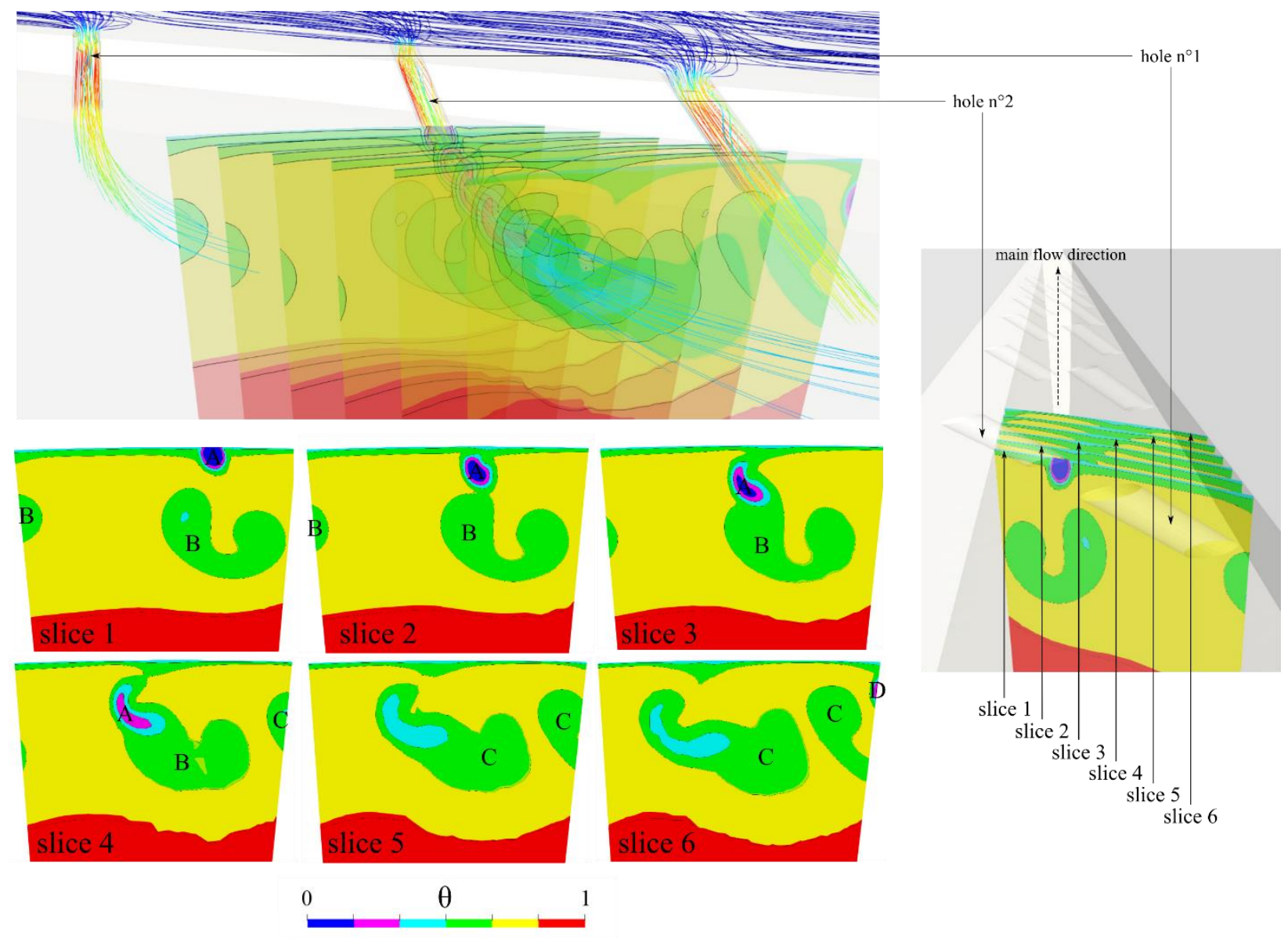

Fig. 17 Conjugate RANS simulation for a $45^{\circ}$ compound angle: temperature field in the hot channel over six slices perpendicular to the jets. Streamlines are colored by the velocity magnitude.

The same analysis is made for a $0^{\circ}$ compound angle, in Fig. 18. The slices, perpendicular to the jets, show that jets from two consecutive holes, do not mix because of the staggered pattern. Even if the fluid temperature close to the wall slowly decreases, no cold air layer is efficiently maintained close to the wall. Markers $[\mathbf{A}]$ and $[\mathbf{B}]$ refer to the jets from hole number 2 and hole number 1 respectively. 


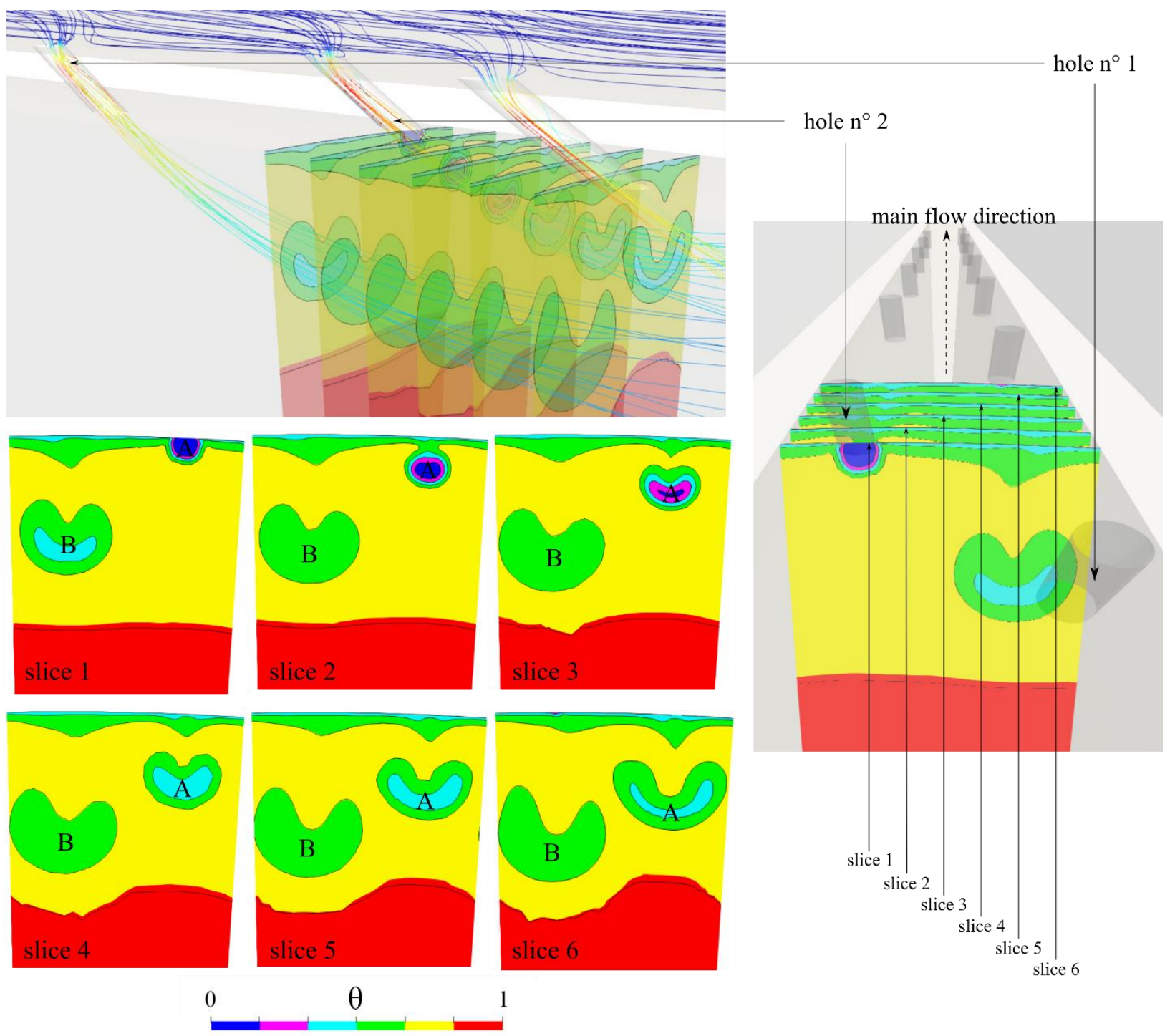

Fig. 18 Conjugate RANS simulation for a $0^{\circ}$ compound angle: temperature field in the hot channel over six slices perpendicular to the jets. Streamlines are colored by the velocity magnitude.

\section{Conclusion}

A detailed experimental database for effusion cooling has been generated. The wall temperature distribution of twelve test cylinders has been measured by infrared thermography, providing the cooling efficiency of various hole patterns. In particular, the effect of the compound angle is shown to be significant. A specific methodology is derived to model the boundary conditions for the associated RANS simulations. Results show that the temperature evolution can be predicted by the code in the multiperforation area, but the cooling efficiency can be overestimated for high values of the compound angle. In the downstream area, RANS simulations do not predict well the mixing between the cooling film and the hot air, leading to an inaccurate behavior of the wall temperature in this region.

Moreover, a detailed analysis of the RANS simulations has been conducted in order to better understand the effects of the compound angle on the cooling film generation and on the heat fluxes at the wall. For a $90^{\circ}$ compound angle it shows how the cold air injection creates an aerodynamic barrier against the incident hot air and how it creates a cold air layer close to the wall, reducing efficiently the heat exchanges. On the contrary, for a fully axial hole pattern, the jets do not interact enough between two consecutive holes to create an effective cooling film. For a $45^{\circ}$ compound angle, the cold air jets are added to each other from one hole to another, and a film can be created, but the lateral 
spreading is not good. High compound angles offer a better protection of the wall in the multiperforated area, providing a very high cooling efficiency.

\section{References}

[1] R.E. MAYLE and F.J. CAMARATA. Multihole cooling film effectiveness and heat transfer. In AIAA / ASME Thermophysics and Heat Transfer Conference, Boston, Massachusetts, 1974

[2] M.E. CRAWFORD, W.M. KAYS, and R.J. MOFFAT. Full-coverage film cooling. Part 1: Comparison of heat transfer data for three injection angles. Journal of Engineering for Power, 102: 1000-1005, October 1980

[3] C. ZHANG, B. SONG, Y. LIN, Q. XU, and G. LIU. Cooling effectiveness of effusion walls with deflection hole angle measured by infrared imaging. Applied Thermal Engineering, 29: 966-972, 2009

[4] K.T. McGOVERN and J.H. LEYLEK. A detailed analysis of film cooling physics. Part II: Compound-angle injection with cylindrical holes. ASME International Gas Turbine \& Aeroengine Congress \& Exhibition, Orlando, Florida, June 2 - June 5 1997

[5] B. MICHEL, P. GAJAN, A. STRZELECKI, N. SAVARY, A. KOURTA, H-C. BOISSON. Full coverage film cooling using compound angle. Comptes-Rendus Mécanique, Combustion for aerospace propulsion

[6] S. MENDEZ. Simulation numérique et modélisation de l'écoulement autour des parois multi-perforées. $\mathrm{PhD}$ thesis, Université de Montpellier II, 2007

[7] D. LAHBIB. Modélisation aérodynamique et thermique des multiperforations en LES. PhD thesis, Université de Montpellier, 2015

[8] G. ARROYO-CALLEJO. Modélisation thermique avancée d'une paroi multiperforée de chambre de combustion aéronautique avec dilution giratoire. Modélisation et simulation. $\mathrm{PhD}$ thesis, Institut Supérieur de l'Aéronautique et de l'Espace, 2016

[9] R. BIZZARI. Aerodynamic and thermal modelling of effusion cooling in LES. Phd thesis, INP DE TOULOUSE, 2018

[10] G. COTTIN. Contribution à la modélisation thermique d'une paroi multiperforée. PhD thesis, Institut Supérieur de l'Aéronautique et de l'Espace, 2012

[11] P. GRENARD, and D. SCHERRER. A modified wall boundary condition for multi-perforated walls. International Journal of Heat and Mass Transfer, 67: 16-24, 2013

[12] A.R. BYERLEY, P.T. IRELAND, T.V. JONES, and S.A. ASHTON. Detailed heat transfer measurements near and within the entrance of a film cooling hole. Gas Turbine and Aeroengine Congress, Amsterdam, 1988 